\title{
USING NIGERIAN ENGLISH IN AN INTERNATIONAL ACADEMIC SETTING
}

\author{
UNA CUNNINGHAM
}

Stockholm University

\begin{abstract}
This study examines the English pronunciation of a group of Nigerian students at a university in Sweden from the point of view of their intelligibility to two groups of listeners: 1) native speakers of English who are teachers at the university; 2) nonnative speakers of English who are teachers at the university. It is found that listeners who are accustomed to interacting with international students do better than those who are not, and that native speakers of English do no better or worse than non-native listeners. The conclusion is drawn that locally useful varieties of Nigerian English may not easily be used as for wider communication and that students preparing to study abroad would find it useful to gain access to a more widely intelligible variety.
\end{abstract}

\section{Background}

Many students from all around the world find their way to universities in Sweden. There are a number of reasons why Sweden is attractive to international students. The standard of living is high, and so is the standard of education. In addition, it is well known that many Swedish people speak English. Swedish universities offer a fair number of Master's programs and a few undergraduate programmes taught through the medium of English. It is not difficult for international students to study in Sweden, even if they have no knowledge of the Swedish language. Another, quite compelling, reason for the interest Swedish universities have attracted from international students is the fact that Swedish higher education had until recently no tuition fees, not even for students from outside of Europe. Many students have realised that in Sweden they have the chance of getting a world-class education without paying fees.

Many Nigerian students who come to Sweden to study English have received most or all of their previous education through the medium of English. It comes as a shock in many cases for these students to find that they are not viewed by their teachers in Sweden as native or near-native speakers of English. They may fail language proficiency courses and find that their English does not work as well as they expect it to in communication with their teachers and with other international students, in particular those who are non-native speakers of English.

The influx of students from other parts of the world has not been entirely without problems. There are a number of inconsistencies between the Swedish education system and its counterparts in other countries. One problem we have had is with the way foreign qualifications are judged by the Swedish National Agency for Service to Universities 
and University Colleges who centrally administer admissions to Swedish universities. Each year the Agency produces a handbook where the national qualifications in many countries are listed, explained and compared to the Swedish qualifications upon which the admissions system is based. Unfortunately it appears that in a number of cases the Swedish system is overly generous in its conversion of foreign grades. For example, it is necessary for students who have attended school in Nigeria to achieve a grade 8 (the lowest pass grade) in English O-level (SSCE/WASSCE). This is deemed as equivalent to the Swedish upper secondary course English B, which is in turn deemed equivalent to IELTS level 6.0 with at least 5.5 in each section of the test. This fulfils the English language prerequisites for any programme of study in any faculty at any Swedish university. Ironically, it appears that at least in the past, Nigerian universities do not accept students to any faculty with less than a credit (grade 6) in O-level English (SSCE/WASSCE) (Ufomata 1996).

The Swedish system of higher education was designed to cater for the needs and expectations of Swedish school leavers. For many years this was adequate. When Sweden entered the EU in 1995 the number of international students increased with exchange schemes such as the Socrates-Erasmus programme which funds and facilitates the exchange of students and staff between universities in Europe. Such students stay for a semester or a year and return to their home universities with their credits to take their degree there. The influx of students from beyond the EU coincided with the introduction of degree programmes (as opposed to short courses which the student collects until the appropriate number of credits and a degree thesis have been achieved allowing the student to apply for a degree). In the global higher education market, degree programmes are much more transparent and attractive than the loosely bound selection of courses which leads to a degree that has been usual, at least in the humanities, in Sweden.

The EU has, through what is known as the Bologna process, attempted to impose a degree of uniformity on European higher education. It is, in theory, possible for students to wander from one European university to another, taking their credits where they may. Of course, in practice, things are not always that simple, but there is at least a level of understanding of the way the system works in other parts of Europe. When students from other parts of the world apply to Swedish courses and programmes they may find that their qualifications are not well regarded. Students from Pakistan, for example, may find that they need to have completed both a BA and an MA to be deemed to have a qualification equivalent to a Swedish bachelor's degree. Students from Russia may find, to their dismay, that only three of their five years of university education will be considered.

These circumstances lead to a situation where many students are admitted to study at too high a level due to the prerequisites being inappropriately low. In fact such students often have a primary problem with insufficient proficiency in English language. The University provides an English language needs analysis to discover such cases early on (in the first week of study) so that students can be offered courses in English for academic purposes during one or sometimes two semesters, before proceeding to their planned programme of study. This preparatory study improves students' proficiency levels while simultaneously introducing them to the means, methods and models of learning which shape the student experience at a Swedish university. 
English has no official status in Sweden, which means that Sweden is part of Kachru's expanding circle (Kachru 1992). In Sweden, the requirement of English language proficiency for the study of English at university level is set to match that held by Swedish school-leavers who have taken two years of English at upper secondary school. Previously such students will have studied English for at least 7 years at primary and lower secondary school. In addition, they are bombarded by English from TV, cinema, music and computer games. They have ample opportunity to hear English and most young people can switch to English with minimal inconvenience when they need to, which is fairly often, given that Swedes travel extensively and cannot expect to meet only Swedish speakers outside Sweden and that Sweden has many international visitors. Swedish young people possess considerable communicative competence in English. While their speech may be accented and their grasp of the vagaries of English grammar tenuous, they speak and understand English adeptly. Consequently, university English courses in Sweden are generally designed to teach grammatical accuracy and academic reading and writing skills at the initial level, rather than pronunciation and communication, moving quickly on to the kind of courses in English language, linguistics, literature and culture that can be found at universities anywhere in the English-speaking world.

What then do we require of students who are to take part in our courses in terms of English language proficiency? One criterion for the required level in the needs analysis is that students need to be able to understand native and non-native speakers of English speaking clearly and at normal tempo, which is what they need to be able to do if they are to take part in classes. Another is that they need to be able to express themselves coherently orally and in a free writing task. Yet another part of the needs analysis is a grammar test, corresponding to the IELTS levels 5.0 and 6.0 which are the levels required for our preparatory courses and ordinary undergraduate and graduate courses respectively.

To address the needs of students who are admitted to the university with less English proficiency than we require as shown by the needs analysis, we have designed our preparatory courses in English for academic purposes. In fact we have found that some Swedish students also appreciate these courses, either because they have only one year of upper secondary English, or because they have been away from education for some years and feel that their English needs refreshing before they continue. Even the occasional native speaker of English turns up on our courses for a number of reasons, often involving limited educational opportunities. Our needs analysis will pick up these speakers through their lack of certainty regarding the grammaticality of Standard English constructions and their written disfluency. For students who have learned English as a foreign language in their home country in the so-called expanding circle, it may be disappointing to find that the level achieved is not adequate for study in Sweden, and some do insist on disregarding the advice of their teachers and continuing on the programme or course to which they have been admitted, generally with disappointing results. For Swedish students and for the occasional inner circle speaker from the UK or the US, the preparatory courses offer a chance to remediate the gaps in their English in a context which is not face-threatening. The students who find it hardest to accept a disappointing result in the needs analysis are those who come from the outer circle, those for whom English is a second language, often the language of their education. 
There is a serious problem here which is faced by all international academic environments. While, on the one hand, speakers of what McArthur (2002) calls New Englishes rightly demand full respect and recognition of these as legitimate varieties of English, they, like some of the Old Englishes such as my own Northern Irish English are not always ideally suited to international communication. As an educated speaker of Northern Irish English, when I left Northern Ireland to study in Britain, I quickly learned to modify my pronunciation to facilitate communication with non-Northern Irish interlocutors. Significantly, this can be done without compromising speaker identity as, in my case, a person from Northern Ireland. Initially I was not easily understood and my pronunciation was the object of comment. Failure to change my more "extreme" pronunciations might eventually have led to those I interacted most with getting used to my way of speaking, but the social and educational cost would be considerable. The result is that I, like many speakers of non-standard accents and dialects, switch between accents depending on my interlocutor and the communicative situation.

There is a significant distinction to be made at this point between English and Englishes. One of the definitions of a language as opposed to a dialect refers to the criterion of mutual intelligibility. While I would not like to suggest that the less widely intelligible accents of English are not English - we are after all talking about accents rather than syntactic or lexical variation - English is a very special case. We ask more of English than has ever been asked of any language in our history. Not only is it an important lingua franca, allowing genuine international communication, it is also a local living language for millions of everyday speakers in many different countries. But we are fooling ourselves if we claim that a speaker can wander from one communicative situation to another without modifying his or her English according to the communicative situation. Two speakers of any variety of English will be able to speak together in a different way than if one of them were to converse with a speaker of another variety in another place, and in yet another way if speaking to an EFL or ESL learner (even one who has the same variety of English as a target for their learning) whose proficiency may well be limited.

The problem may arise as a consequence of postcolonial insecurities and defensiveness regarding the status of New Englishes. If there is indeed a Standard Nigerian English pronunciation, which seems relatively problematic given the variation described in e.g. Banjo (1971), Bamgbose (1995) and Ufomata (1996), it may not be very useful for international communication, just as can be said of Glasgwegian and various Northern Ireland accents, not to mention some kinds of southern US accents, or broad Australian, or Scouse, Geordie or any other well-defined accent of English. No linguist would question the legitimacy of any of these inner or outer circle accents. What happens is that these are not adequate for international or even interregional settings. To say this is not in any way to denigrate these accents-they are obviously linguistically adequate and important carriers of sociolinguistic markers. But it is important to separate the functions of English in local and international communication. English as a language of international communication is not the same as speaking to your neighbour in Glasgow, Birmingham, Hong Kong or Lagos. There is little point in insisting on the right to use the particular forms and phones that mark a speaker as a speaker of a particular variety if there is a failure to communicate. 
It does, of course, take two to communicate. A good deal has been written about the need for native speakers of inner speaker varieties to become more informed and tolerant listeners such that they might be better prepared to perceive and interpret unfamiliar accents of English (Phillipson 1992). There is a good deal of individual variation in how flexible listeners are in their attempts to understand what they are hearing, and probably the personal language history of the listener will be relevant in how easily they understand other accents (Cunningham 2009). In addition, experience of the accent in question will also be significant in how easily an individual can understand a particular accent (Kirkpatrick, Deterding et al. 2008; Rooy 2009).

There is a difference, however, between attempting to understand a speaker of English as a foreign language (EFL) who has a foreign accent and attempting to understand a speaker of a New English who is a speaker of English as a second language (ESL) and who has an accent associated with that variety of English. The two situations are similar, but there is a difference in speaker and listener expectations. Both speakers will have had the experience of being a learner of English and presumably of having instruction in pronunciation of English. Both will often have learned English from a teacher with their own language background in a class of others with the same background. However, the EFL speaker will often have had British or American English as a model for their learning, while the ESL speaker may well have had the New English variety in question as their model. Where there is a breakdown in communication these speakers may behave differently. The speaker of a New English has different expectations of his or her variety being met with respect and may be extremely reluctant or unable to offer alternative pronunciations, finding that an intolerable infringement of their speaker integrity. The EFL speaker may be better prepared to try different pronunciations and formulations.

Jenkins has led the way in the description of English as a language of international communication (EIL) e.g. Jenkins $(2002,2005)$ and where at least one party is not a native speaker of English, English as a Lingua Franca (ELF) e.g. Jenkins (2006, 2009), Berns (2008), Seidlhofer (2009) and Watterson (2008). In this context, it is unproblematic to discuss matters such as an ELF core phonology (Jenkins 2000). Crystal $(2003,124)$ and Graddol $(1997,56)$ discuss the possibility that English might develop into a number of mutually unintelligible varieties, but that this would be mitigated by a parallel competence being built in a globally standard English for international communication, leading to a diglossic situation which is reminiscient of that currently operating in countries like Sweden where English is used as soon as a non-Swedish participant is involved while Swedish is used between Swedes. The data presented in this paper suggests that this may already be a necessity.

Smith and Nelson (1985) teased out the distinction between intelligibility, comprehensibility and interpretability. Intelligibility is the concern of this paper, and deals with word or utterance recognition, such that a listener would be able to transcribe an utterance which he or she finds intelligible.

Intelligibility is not an absolute. Intelligibility is a factor related to a specific speakerlistener communicative event. An utterance or a speaker cannot be said to be intelligible or not intelligible in any absolute sense. A speaker can be more or less intelligible to different speakers in different situations. 
A lack of intelligibility is a problem for speaker and listener alike, and a good deal of work has been done on various aspects of intelligibility, e.g. Smith and Rafiqzad (1979), Smith \& Nelson (1985), Jenkins (2002) and Berns (2008). Smith and Nelson (1985) point out that there is general agreement that it is unnecessary for every speaker of English to be intelligible to every other speaker of English, but that we do need to be intelligible to those with whom we are likely to communicate in English.

Naturally, the time is long past when native inner circle speakers are the only legitimate judges of what is intelligible, and few would maintain that native speakers are automatically more intelligible than non-native speakers e.g. Smith and Rafiqzad (1979). As the number of speakers for whom English is one of a number of languages grows and has long ago exceeded the number of so-called native (monolingual?) speakers of English, the imagined native speaker is not often the implied interlocutor for learners of English in either EFL or ESL situations.

This study uses data from Nigerian students and thus it is relevant to consider the role and status of English in Nigeria. A good deal has been written on this topic which is confounded by the multitude of languages spoken in the country (some 400 in some sources e.g. Gut and Milde 2002). The colonial history of countries such as Nigeria have led to a situation where English is retained as a language of business, education and media as well as interethnic communication (Gut 2007), although, Nigerian Pidgin English also serves for interethnic communication. Due to a complex mesh of factors including linguistic attitudes and language policies in the outer circle countries in general and Nigeria in particular, these speakers may not appreciate their first languages, sometimes referring to them disparagingly as dialects, vernaculars or local languages. A good deal has been written and will continue to be written about the need for African languages to take a more prominent role in the lives of the people of Africa, e.g. (Prah 2002). The role of English in Nigeria, as elsewhere in Africa, and the attitudes of Nigerians to English and other Nigerian languages are sensitive topics.

The distinction between second language varieties of English such as Standard Nigerian English and learner varieties of those with Standard Nigerian English as their target variety is far from clear cut. The nature of the relationship between English-based varieties in Nigeria has not, to my knowledge, been fully explored. In other comparable postcolonial contexts a continuum has been described which spans from a basilect, perhaps represented here by Nigerian Pidgin English to an acrolect which would be close to the British English which was the variety once imposed upon Nigeria, as suggested by Ufomata (1996).

Adamo (2007) writes that "English has itself (to a certain extent at least) become a Nigerian language". She points to nativization of English as indexical of its integration into the culture of the community. Like the Nigerian author, Achebe, she sees Nigerian English as having "communion with its ancestral home but is altered to suit its new surrounding" (Achebe 1975). She writes further that "When a people are alienated from their language(s), as is the case in Nigeria today, they gradually become alienated from their culture" She argues that English, however nativized, will not serve as a national language, and calls for an indigenous language to take that place. At the same time she is realistic and points to the efforts made to standardize, nativize and codify Nigerian English to enable it as a carrier of Nigerian culture. 
The status of Nigerian English as a variety of English has been questioned (Ajani 2007). This is certainly a central question if we are to be able to decide whether the English spoken in Nigeria is a variety of English which can carry a culture or if we are to regard it as a learner variety. In the words of Kachru "what is 'deficit linguistics in one context may be a matter of 'difference' which is based on vital sociolinguistic realities of identity, creativity and linguistic and cultural contact in another context" (Kachru 1991). Ajani (2007) sets the position of a standardised Nigerian English against the early position of English teachers in Nigeria who refuse to accept any model but the native British model. Ajani relates this debate to the US Ebonics debate, rejecting AAVE as a legitimate variety for use in education. He further questions whether speakers of one of the 400 languages of Nigeria, e.g. Hausa, will sound the same when speaking English as will a speaker of another language, e.g. Yoruba or Igbo.

Bamgbose (1982) views the emergence of a Nigerian English as a natural outcome of the language contact situation in the country. He accounts for three mechanisms at work in generating usages in the Nigerian English: the interference, deviation and creativity approaches involving "interference" from the mother tongue (or possibly Nigerian Pidgin English), "deviation" from the native British norm and the creative inclusion of elements of local languages as well as English to create new items respectively. Bamgbose rejects the native model for Nigerian learners and suggests that the educated speaker of Standard English be the model. This standard has not, however been well described.

Schneider (2003) compares the evolution of postcolonial Englishes in language contact situations to the acquisition of a second language such that the phonology of such new varieties will display features that resemble transfer from the phonology of "indigenous languages". This view is shared by Hickey (2004:519) who writes on cluster simplification in Asian and African Englishes that "this is determined largely by the phonotactics of the background language(s). In the case of Nigeria, there are a multitude of such background, or substrate languages. It is estimated that almost 400 languages are spoken in Nigeria (Bamgbose 1971, Agheyisi 1984). This does, of course, depend on how the languages are defined. Prah (2009) claims that the number of languages, as defined by criteria of mutual unintelligibility might be far fewer. He states,

\footnotetext{
"What is not easily recognized by many observers is that most of what in the literature, and classificatory schemes, on African languages passes as separate languages in an overwhelming number of cases are actually dialectal variants of "core languages." In other words, most African languages can be regarded as mutually intelligible variants within large clusters (core languages)."
}

Ufomata (1996) offers an account of the continuum that exists with native-like accents at one end (deemed essential for a career as newsreader) and "other varieties which can be defined negatively in relation to these standard accents". Ufomata goes on to say that the Nigerian standard is socially accepted and internationally intelligible. Bamgbose (1995) suggests that this accent should be taught in schools. Ufomata accounts for some of the main features of Educated Spoken Nigerian English, describing them with reference to RP phonemes. These are:

- The vowels of ship and sheep are both pronounced [i]

- Food and foot are both pronounced with [u] 
- Bath and bag are both pronounced with [a]

- The vowels of play and plough are monophthongized to [e] and [o] respectively

- The initial consonants of thin and then are pronounced [t] and [d] respectively

- Heavy nasalization of vowels preceding nasals and the dropping of word-final nasals.

Previous work on the intelligibility of Nigerian English has indicated that rhythm and intonation are the biggest problem (Stevenson 1965). Syllables that would be unstressed in other varieties of English may not be reduced in any way in this variety. This study will add to our knowledge about the intelligibility problems experienced by Nigerian English speakers and their non-Nigerian interlocutors.

Banjo (1971:169-70) in an often cited account describes four discrete varieties of Nigerian ranging from what he calls Variety 1 which is marked by wholesale transfer of phonological, syntactic, and lexical features of Kwa or Niger Congo to English, spoken by those whose knowledge of English is very imperfect and neither socially acceptable in Nigerian nor internationally intelligible, through Variety 2 and Variety 3 which are described as progressively closer to standard British English in syntax, semantics and lexis, though still different in phonetic features with increasing international intelligibility to Variety 4 which he describes as identical to standard British English. This last may correspond to the "newsreader variety" described by Ufomata (1996). It seems likely that there is in fact a continuum ranging perhaps even from a basilect represented by Nigerian Pidgin English through Standard Nigerian English to the British-like acrolect.

\section{Material and Methods}

The three students who have provided the stimuli for this study are young men aged between 23 and 34 from Nigeria. They came to Sweden to study a bachelor's programme in English language, literature and culture. When they arrived to take up their studies they took part in the needs analysis mentioned above, and all three of them were found to be have an inadequate level of English proficiency on both their oral skills (receptive and productive) and their mastery of standard English grammar. The students involved in this study have been educated in English-medium schools since primary school. When asked which is their first or native language, all three indicated that English was their first language. This is in spite of the fact that further enquiry revealed a) that they did not encounter English until they began primary school, b) that English was not the language they used to speak to each other, choosing the Nigerian language Igbo for that purpose in the case of two speakers (the third speaker did not speak or understand Igbo) and Nigerian Pidgin English otherwise, c) that English was not the language they used to talk to their families and d) that their English was not a language they mastered in terms of grammatical consistency, vocabulary size and written or spoken fluency according to the results of our needs analysis. Their English appears to all intents and purposes to be a learner variety. The distinction between learner varieties and New Englishes is, of course, not always easy to draw, and these young men have presumably had Nigerian English as a model and target for their English learning. 
The 21 listeners were recruited from among students and staff at a Swedish university, both those who regularly come into contact with international students and those who do not. Seven of the listeners were native speakers of English from the England, the US, Scotland, Ireland and Australia and 14 were non-native speakers of English with French, Swedish, Russian, Italian, Finnish and German as their first languages. Six of the native English speakers and five of the non-native English speakers had extensive experience hearing international Englishes of many kinds through contact with our extremely international student body. Others had less such contact and experience.

The three speakers each recorded a set of material including a text, a wordlist, a set of words contrasting high front vowels and postvocalic consonant voicing embedded in carrier phrases in phrase final and non phrase final position, a set of semantically meaningful sentences and a set of semantically unpredictable (but still grammatical) sentences and a set of true/false questions. The last three items on this list are the same material as used in another study reported in Munro and Derwing (1995). The stimuli used in this study were selected from the semantically meaningful sentences. These sentences were designed to include some sounds and sound combinations that are generally challenging for many ESL and EFL speakers in sentences where the contexts is not especially helpful to the listener. In other words, comprehension will not be an aid to intelligibility, while the sentences are still considerably more natural than the test words in carrier phrases that were also recorded.

Eight sentences were used in this study, uttered by speaker N1 apart from sentences 5 and 8 . Sentences 4 and 8 are the same, but were spoken by two different speakers.

1 A big farmer lifts a large load.

2 A confident guy viewed a natural scene

3 A fair judge gives a second chance

4 A hundred sheep took a dangerous trip

5 My girl climbed a red car (speaker N2)

6 A pool is better than seventeen orange trees

7 A thin lady taught a musical language

8 A hundred sheep took a dangerous trip (speaker N3)

Speakers were presented with the stimuli using an online test facility built into the learning platform used at the university. Listeners heard the utterances individually through headphones and they could listen as many times as they wanted to the utterance and were then asked to write what they heard. They could take the test online at a time convenient to themselves.

\section{Results}

Table 1 shows the results provided by the listeners for the first sentence, A big farmer lifts a large load as uttered by speaker N1. The listener responses are divided into those obtained from native vs. non-native speakers of English, and those used or not used to international Englishes. As can be seen, the responses were very varied, from the imaginative It is summer, live the blue life to two cases, one native and one non-native listener who heard the utterance as intended by the speaker. 


\begin{tabular}{|l|l|l|}
\hline $\begin{array}{l}\text { Used } \begin{array}{l}\text { to } \\
\text { Enternational } \\
\text { Englishes? }\end{array} \\
\text { yes }\end{array}$ & $\begin{array}{l}\text { It is summer, live the blue life } \\
\text { A big farmer lifts a large loot } \\
\text { A big farmer leaves a large lodge } \\
\text { The big farmer lives large loge } \\
\text { A big farmer lives a large looge? } \\
\text { A big farmer lifts a large load. }\end{array}$ & $\begin{array}{l}\text { A big farmer leaves a large Luke. } \\
\text { The big farmer lives in large lu??? } \\
\text { A big farmer lives in a large luge } \\
\text { A big farmer lives a large luuk?? } \\
\text { A big farmer lives in large louge }\end{array}$ \\
\hline & A big farmer lives a large look. & $\begin{array}{l}\text { A big farmer lives a large loot } \\
\text { The big farmer lives in a large loot } \\
\text { A big farmer lives a large... } \\
\text { no }\end{array}$ \\
& & $\begin{array}{l}\text { A big farmer lives in large ? } \\
\text { A big farmer leaves a large look... } \\
\text { A big farmer lives in a large } \\
\text { loudge } \\
\text { The large farmer lives a large } \\
\text { lodge } \\
\text { The big farmer leaves/lives a } \\
\text { large? }\end{array}$ \\
\hline
\end{tabular}

Table 1. Responses from native and non-native English speakers used and unused to international Englishes listening to speaker N1 saying A big farmer lifts a large load.

What we see here is that the listeners have difficulty reconstructing the elided / $t$ / in lifts; they are unsure whether the intended vowel gives leaves or lives. They are interpreting the word load produced with a [u] loot, look or Luke to name just a few, and the speaker's slightly affricated /d/ in load is interpreted as lodge or large. The listeners are doing their best to listen with an open mind as they try to make sense of the utterance. This leads to incomprehensibility as well as unintelligibility in Smith and Nelson's (1985) terminology.

Other stimuli sentences produce similarly creative reconstructions as listeners do their best to comprehend the only sporadically intelligible speech of the speakers. Table 2 summarizes the responses, with the intended word at the left of each row and the listener perceptions in subsequent columns.

\begin{tabular}{|c|c|c|c|c|c|}
\hline \multicolumn{6}{|c|}{ Speaker N1 } \\
\hline $\mathrm{a}$ & a 5 & the15 & & & Other 1 \\
\hline lifts & lifts 3 & leaves 4 & lives 13 & & Other 1 \\
\hline load & load 2 & loot 3 & $\begin{array}{l}\text { luke/luuk/loo } \\
\text { k } 4\end{array}$ & $\begin{array}{l}\text { lodge } \\
\text { etc. } 7\end{array}$ & Other 5 \\
\hline confident & confident 16 & competent 1 & coffee 3 & & Other 1 \\
\hline guy & guy 4 & car 3 & guard 4 & girl 3 & Other 7 \\
\hline viewed & viewed 17 & filled 1 & & & Other 3 \\
\hline
\end{tabular}




\begin{tabular}{|l|l|l|l|l|l|}
\hline scene & scene 9 & sin 2 & & & Other 10 \\
\hline fair & fair 10 & friend 2 & & & Other 9 \\
\hline judge & judge 5 & choice 4 & church 1 & george 6 & Other 5 \\
\hline gives & gives/give 15 & & & Other 6 \\
\hline sheep & sheep(s) 14 & ship(s) 3 & & & Other 4 \\
\hline dangerous & dangerous 18 & & & Other 3 \\
\hline pool & pool 17 & poo 2 & & Other 2 \\
\hline $\begin{array}{l}\text { orange } \\
\text { trees }\end{array}$ & orange tree(s) 16 & & & Other 5 \\
\hline thin & thin 6 & teen/team 8 & tin 2 & & Other 5 \\
\hline lady & lady/ladies 16 & & & Other 5 \\
\hline Speaker N2 & girl 5 & gate/gay 5 & & & Other 11 \\
\hline girl & climbed 13 & & & Other 8 \\
\hline climbed & red 17 & & & Other 4 \\
\hline red & car 14 & & & Other 7 \\
\hline car & Speaker N3 \\
\hline sheep & sheep(s) 14 & ship(s) 5 & & Other 2 \\
\hline
\end{tabular}

Table 2. Summary of intelligibility issues in all eight stimuli sentences spoken by speakers $\mathrm{N} 1, \mathrm{~N} 2$ and $\mathrm{N} 3$ showing numbers of responses

So what we see here is that speaker N1 (like N3) does not distinguish between the vowels in e.g. sheep and ship as evidenced by the confusion experienced by listeners in these words as well as lifts, scene and thin. As mentioned above, his reduction of consonant clusters or affrication of consonants in the coda lead to misperception of the words lifts, competent and judge. We can further note that his realisation of post vocalic nasals as nasalised vowels misleads or confuses the listeners in the words confident, scene and thin. His monophthong pronunciation of the vowels in guy and fair causes many listeners to guess wildly at the speaker's intention. For speaker N2, the very open [a] pronunciation of the vowel in car confuses a third of the listeners, while only less than a quarter of the listeners could reconstruct girl from what they actually heard.

The listeners who came closest to hearing the speakers' intended words were both native and non-native speakers of English, but they were both quite used to hearing international Englishes. The listeners who did least well were in one case a native speaker who does in fact have experience of international Englishes, and the non-native inexperienced listeners.

\section{Discussion}

There is nothing unexpected about the results reported above. Jenkins $(2000,2002)$ has posited that certain parameters need to be upheld if speech is to be internationally intelligible. These speakers of Nigerian English, perhaps even Standard Nigerian English, as described by Ufomata (1996) and Bamgbose (1982) do not maintain the distinctions outlined by Jenkins, and their speech as elicited for this study is patently not 
intelligible to the non-Nigerian native and non-native speakers of English who are listening to them.

Some descriptions of Nigerian English compare the variety to RP as a target variety, e.g. Ufomata (1990, 1996). But the question of the status of Nigerian English as a variety of English or a New English is very relevant here. If Nigerian English is a legitimate variety of English, there is no reason why it should not be used as a model for Nigerian learners of English. Eka (2003:35) writes that this is "the variety of world Englishes spoken and written by Nigerians within the Nigerian environment". So the question of whether or not the features of Nigerian English are to be viewed prescriptively as errors or descriptively as features of Nigerian English depends of the speakers' intentions. If they are intending to speak Nigerian English, they are not making errors - they are succeeding in their intention. But if they are aiming at a more internationally intelligible variety, then the features of their pronunciation can be seen as errors and may be corrected if the students take part in classes in English pronunciation (which the speakers in this study actually did as part of their course in Sweden. This Nigerian English is not a language of wider communication as defined by Bamgbose (1991).

Smith and Nelson (1985) suggest that if a listener expects to understand a speaker it is more likely that this will indeed be the case. Nonetheless, the listeners in this study do appear to expect certain things of the utterances they hear. In line with the ideas expressed in Jenkins' Lingua Franca Core (Jenkins 2002), there are some sounds that should not be elided and some vowel distinctions that should not be neutralised if intelligibility is to be maintained.

It is not only the pronunciation that is affected by the first language. Listeners will listen according to the salient cues to vowel and consonant identity, voicing, etc. that operate in the languages they speak, particularly in their first languages. Native speakers of English will identify postvocalic voicing in words like bat vs bad according to the length of the vowel rather than the vocal fold vibration (voicing) during the stop phase of the postvocalic consonant. In fact, in the speech of many individuals, the stop will be devoiced, though still lenis (Cruttenden 2008). If a speaker of another variety is transmitting other cues to postvocalic voicing but failing to shorten the vowel before a voiceless consonant, the native speaking listener may fail to pick up on the intended voicing. In any kind of communication involving speakers of different varieties, listeners need to be as flexible as they are able to be, although, unless they have considerable experience of listening to a particular speaker they may not be able to read the cues transmitted by the speakers.

Levis (2005) explicates the difference between nativeness and intelligibility as learner targets (see also Cunningham (2009)). Hung (2002) questions the need to "improve" non native pronunciation of English. He asks why teachers should modify learners' naturally acquired phonology of English and when it is worth the learners' and their teachers' efforts to do so. The answer Kirkpatrick, Deterding et al. (2008) offer to the question is that intelligibility criteria must be decisive here. The research of Kirkpatrick, Deterding et al has taken place in the Hong Kong context. In Nigeria too, we are dealing with learners of English as a second, not a foreign language and Nigerian English is a Nigerian language and is used to convey speaker identity. International intelligibility may not, however, be high on speakers' lists of priorities. Failure to speak in a way that is intelligible to a wider circle of listeners than that found in a local 
Nigerian context is only problematic if the speech is indeed directed to non-Nigerian listeners. Even then, it is no more acceptable to insist that a Nigerian English speaker change his or her pronunciation to suit the listener than it would be to require the same of a Welsh, Australian or Northern Irish speaker.

There are two ways to go here. The Nigerian (Welsh / Australian / Irish) English speaker can adjust his or her pronunciation, moving along the continuum to a less regionally marked pronunciation, if he or she has access to such a variety, or the listener can learn more about Nigerian (Welsh / Australian / Irish) English in order to become a more experienced and "in tune" listener, what Catford would have described as "lowering one's intelligibility threshold" (Catford 1950). Now in the case of a nonNigerian listener who is in Nigeria, the latter alternative is reasonable and realistic, but in the case of a Nigerian English speaker in the diaspora, it is not realistic to expect one's listeners to be prepared for perceiving Nigerian English. The speaker must adjust his or her speech or face having interlocutors miss a good deal of what is said.

In discussion of the use of English as a language of international communication, or English as a lingua franca, mutual intelligibility is a major concern (Cunningham 2009; Rooy 2009). Without intelligibility, communication is severely hampered. If speakers of Nigerian English mean to use their English as a language of wider, or international communication, they need to move along the continuum that is Nigerian English to a point where they avoid those features that are least helpful to their listeners such as the realisation of postvocalic nasals as vowel nasalisation, the elision of postvocalic $/ 1 /$ and the mapping of English vowels onto a severely reduced set of vowels. This does not in any way mean that they need to speak Standard Southern English, or even to sound anything but Nigerian. It is fully possible to signal one's identity in accent without impairing intelligibility. The educated Nigerian speaker, just as the educated Northern Irish, Scottish or Indian speaker, needs to have access to more than one register. There are situations when such speakers will want to move in the other direction, back along the Nigerian English continuum, when for reasons of credibility, integrity, solidarity and identity it is necessary and desirable to enhance the very pronunciation features that impair international intelligibility.

To conclude then, it would seem that whatever legitimacy this variety might have in a national Nigerian context, it is not particularly useful for communication outside the Nigerian context. If speakers intend to make themselves understood in a pan-African context or further afield such as is the position of the students who come to Europe to study, they will need to modify their pronunciation. This is true of all peripheral varieties, or indeed perhaps all varieties where Jenkins' Lingua Franca Core features are not a part of the phonology. Certainly speakers of some Scottish or Northern Irish varieties of English also need to modify their pronunciation when interregional or international intelligibility is at stake. Efficient communication is a two-way affair. It relies upon speakers and listeners meeting in their expectations, and there will usually be an accommodation of interlocutors to each other (Coupland 1984).

However, it is necessary to balance the phonetic integrity of the speaker with the needs of the listener. Nigerian English is a member of the family of English languages (McArthur 2002). But the speaker needs to have access to a point high enough on the basilect-acrolect continuum that is Nigerian English if international intelligibility is to be achieved. There is a clear need for teaching in English for international communication 
alongside teaching of Standard Nigerian English if Nigerians are not to cut themselves off from international discourse and the wider international community.

In many parts of Africa parents are reported to be enthusiastically seeking English medium schooling for their children from an early age, even from preschool in many cases. A number of African nations have implemented legislation stipulating that children will be educated through the medium of English either from the start or from a certain age. This is far from uncontroversial, as both political opinion and research in bilingual education suggest that children might learn better in the language or languages they actually speak than in a foreign language (Prah 2002; Garcia, Skutnabb-Kangas et al. 2006). The empowerment of the languages of Africa is an important issue and the use of indigenous language in African schools is held by Prah and others to be the only way forward if more than a small English-speaking elite are to have access to academic success. One of the reasons why English-medium schooling is sought after by parents is that they believe it will give the children access to a language of wider communication. While this is the case in many African nations, it may not be the case in Nigeria. In Nigeria, children are schooled in English from an early age, but the variety of English used is naturally Nigerian English. Nigerian English speakers who do not gain access to a more acrolectal variety of Nigerian English as part of their education will not be intelligible to either their fellow Africans or to the wider international community. While the English that is needed as a language of wider communication need not be restricted to the Lingua France Core, Seidlhofer (2009: 243) points out that "ELF and postcolonial Englishes are very different realities on the ground.". The political desire to view all varieties of English as mutually intelligible must not be allowed to stand in the way of speakers of Nigerian English from acquiring a more widely understood pronunciation.

\section{References}

Achebe, Chinua. (1975). Morning yet on creation day. London: Heinemann.

Adamo, Grace. E. (2007). Nigerian English. English Today 231: 42-47.

Agheyisi, Rebecca. N. (1984). Minor languages in the Nigerian context. Word 35: 235253.

Ajani, Timothy T. (2007). Is there indeed a Nigerian English? Journal of Humanities and Social Sciences 1:1. Available at http://www.scientificjournals.org/journals2007/j_of_hum.htm Accessed 27 June 2009.

Bamgbose, Ayo. (1971). The English language in Nigeria. In The English language in West Africa, ed. J. Spencer. London: Longmans.

Bamgbose, Ayo. (1982). "Standard Nigerian English: Issues of identification".In The other tongue: English across cultures, Ed.Braj. B. Kachru. Urbana: University of Illinois Press.

Bamgbose, Ayo. (1991). Language and the nation. Edinburgh: Edinburgh University Press.

Bamgbose, Ayo. (1995). English in the Nigerian environment. In New Englishes: A West African perspective, ed. Ayo Bambgose, Ayo Banjo and Andrew Thomas, 9-26. Ibadan: Mosuro. 
Banjo, Ayo. (1971). On codifying Nigerian English: research so far. In New Englishes: A West African perspective, ed. Ayo Bambgose, Ayo Banjo and Andrew Thomas, 1995, 203-231. Ibadan: Mosuro.

Berns, Margie. (2008). World Englishes, English as a lingua franca, and intelligibility, London: Blackwell Publishing.

Bern, Margie. (2009). English as a lingua franca and English in Europe. World Englishes 28 (2): 192-199.

Catford, John C. (1950). Intelligibility. English Language Teaching 1: 7-15.

Coupland, Nikolas. (1984). Accommodation at work. International Journal of Sociolinguistics 4-6: 49-70.

Cruttenden, Alan. (2008). Gimson's Pronunciation of English. London, Hodder Arnold.

Crystal, David. (2003). English as a Global Language. Cambridge: Cambridge University Press.

Cunningham, Una. (2009). Models and targets for English pronunciation in Vietnam and Sweden. Research in Language University of Lodz, Poland.

Cunningham, Una. (2009. Quality, quantity and intelligibility of vowels in Vietnameseaccented English. In Issues in Accents of English II: Variability and Norm, ed. Ewa Waniek-Klimczak. Newcastle: Cambridge Scholars Publishing Ltd.

Eka, David. (2003). The English language: changes and chances within the Nigerian environment. Journal of Nigerian English and Literature 4: 32-41.

Garcia, Ofelia, Tove Skutnabb-Kangas, and Maria E. Torres-Guzma. (2006). Imagining Multilingual Schools: Languages in Education and Glocalisation. Clevedon: Multilingual Matters.

Graddol, David. (1997). The future of English. London: British Council.

Gut, Ulrike. (2007). First language influence and final consonant clusters in the new Englishes of Singapore and Nigeria. World Englishes 26: 346-359.

Gut, Ulrike and Jan-Torsten Milde. (2002). The prosody of Nigerian English. Available at http://www.lpl.univ-aix.fr/sp2002/pdf/gut-milde.pdf . Accessed 27 June 2009

Hickey, Raymond. (2004). Englishes in Asia and Africa: origin and structure. In Legacies of colonial English, ed. Raymond Hickey. Cambridge: Cambridge University Press: 503-535.

Hung, Tony. T. N. (2002). English as a global language and the issue of international intelligibility. Asian Englishes 5: 4-17.

Jenkins, Jennifer. (2000). The Phonology of English as an International Language. Oxford: Oxford University Press.

Jenkins, Jennifer. (2002). A sociolinguistically based, empirically researched pronunciation syllabus for English as an international language. Applied Linguistics 231: 83-103.

Jenkins, Jennifer. (2005). Implementing an international approach to English pronunciation: The role of teacher attitudes and identity. Tesol Quarterly 393: 535543.

Jenkins, Jennifer. (2006). Current perspectives on teaching world Englishes and English as a lingua franca. Tesol Quarterly 401: 157-181.

Jenkins, Jennifer. (2009). English as a lingua franca: interpretations and attitudes. World Englishes 28 (2): 200-207. 
Kachru, Braj. (1992). Teaching world Englishes. In The Other Tongue, English across Cultures, ed. Braj B. Kachru. Urbana, University Illinois Press.

Kachru, Braj. B. (1991). Liberation linguistics and the Quirk concern. English Today 25: 3-13.

Kirkpatrick, Andy., David Deterding, and Jennie Wong. (2008). The international intelligibility of Hong Kong English. World Englishes 273-4: 359-377.

Levis, John. M. (2005). Changing contexts and shifting paradigms in pronunciation teaching. Tesol Quarterly 393: 369-377.

McArthur, Tom. (2002). The Oxford Guide to World English. Oxford, Oxford University Press.

Munro, Murray J. and Tracey M. Derwing. (1995). Processing time, accent, and comprehensibility in the perception of native and foreign-accented speech. Language and Speech 38: 289-306.

Phillipson, Robert. (1992). Linguistic Imperialism. Oxford, Oxford University Press.

Prah, Kwesi K., Ed. (2002). Rehabilitating African languages : language use, language policy and literacy in Africa: selected case studies Cape Town, South Africa Centre for Advanced Studies of African Society CASAS.

Prah, Kwesi K. (2009). The burden of English in Africa: From colonialism to neocolonialism. Lecture presented at Mapping Africa in the English-Speaking World. University of Botswana.

Rooy, Susan. C. V. (2009). Intelligibility and perceptions of English proficiency. World Englishes 28 (1): 15-34.

Schneider, Edgar. (2003). The dynamics of new Englishes: from identity construction to dialect birth. Language 79: 233-81.

Seidlhofer, Barbara (2009). Common ground and different realities: world Englishes and English as a lingua franca. World Englishes 28 (2): 236-245.

Smith, Larry E. and Cecil. L. Nelson (1985). International intelligibility of English: directions and resources. World Englishes 4(3): 333-342.

Smith, Larry E. and Khalilullah Rafiqzad (1979). English for cross-cultural communication - question of intelligibility. Tesol Quarterly 133: 371-380.

Stevenson, K. J. (1965). Reflections on the teaching of English in West Africa. Journal of Nigeria English Studies Association 32: 227-235.

Ufomata, Titi. (1990). Acceptable models for TEFL. In Studies in the pronunciation of English: A commemorative volume in honour of A.C. Gimson, 212-218, ed. S. Ramsaran. London \& N.Y.: Routledge.

Ufomata, Titi. (1996). Setting priorities in teaching English pronunciation in ESL contexts. London, UCL. Available at http://www.phon.ucl.ac.uk/home/shl9/ufomata/titi.htm. Accessed 27 June 2009.

Watterson, Matthew. (2008). Repair of non-understanding in English in international communication. World Englishes 273-4: 378-406. 